\title{
DETECÇÃO DO LINFONODO SENTINELA NO CÂNCER COLORRETAL
}

DESCRITORES - Neoplasias colorretais. Estádio de neoplasias. Metástase linfática. Biopsia de linfonodo sentinela.

Durante a última década, o estudo do linfonodo sentinela (LS) tem melhorado o estádio anatomopatológico de tumores sólidos, especialmente do câncer da mama e do melanoma, graças ao aumento do índice de detecção de doença nesse linfonodo.

O LS é definido como o(s) primeiro(s) linfonodo(s) ao longo da via de drenagem natural do tumor e representa, portanto, um local de eleição para metástase regional. Por essa razão, nas doenças citadas, a histologia do LS é altamente preditiva do estado linfonodal regional. Permite ao patologista análise criteriosa de um ou de alguns poucos linfonodos, por meio de múltiplas secções ou estudo imunoistoquímico, melhorando a precisão quando comparada ao exame histopatológico de rotina.

Nos pacientes com câncer colorretal, o estudo do LS não só é factível, como identifica vias de drenagem aberrantes e também metástases em salto ("skip metastasis"). A identificação de LS acometido por neoplasia não identificada pelos métodos convencionais, poderá eleger grupos de pacientes para terapia adjuvante.

No câncer colorretal, a ressecção linfonodal é tempo obrigatório da cirurgia oncológica, de tal sorte que, poder-se-ia dispensar a identificação do LS. No entanto, sabe-se da existência de casos de pacientes estágio II com micrometástases não identificadas pelos métodos histológicos convencionais e que se comportam como estágio III. Como é sabido, pacientes do estágio II não são rotineiramente tratados com terapia complementar e, portanto, ao se identificar micrometástases nesse subgrupo, poder-se-ia oferecer o benefício do tratamento complementar.

O trabalho de autoria de BASILIO e FONSECA ${ }^{(1)}$, Detecção de linfonodo sentinela no câncer colorretal - importância, técnicas e resultados, apresentado neste número dos ARQUIVOS de GASTROENTEROLOGIA faz análise randomizada e prospectiva da utilização do método em 31 pacientes com câncer do cólon, usando a injeção de corante em um grupo e, em outro, adicionando colóide radioativo marcado com 99mTecnécio. Os autores descrevem o método e os resultados. A identificação de mais de um LS por paciente mostra que podem existir mais de uma cadeia de linfonodos drenando determinado segmento do cólon e esse fato, antes de ser um óbice à credibilidade do método, representa a oportunidade de mais LSs serem examinados com múltiplas secções e imunoistoquímica, aumentando a exatidão. Outro ponto a ser mencionado seria a reprodutibilidade do método com o objetivo de aumentar a confiabilidade do exame. A utilização do corante e do colóide separadamente talvez possa servir de testemunho um do outro. Quanto à utilização de colóides, sabe-se que são constituídos de partículas de dimensões variadas, o que dificulta a difusão a partir do local de injeção, fato que prejudica a captação das mesmas. Nesse sentido, poder-se-ia utilizar o dextran como traçador, pois apresenta peso molecular definido, não atravessa as membranas capilares e se desloca do local de injeção somente por drenagem linfática. A superposição das técnicas mostrou melhorar a acuidade da pesquisa.

Fato relevante foi o percentual de aumento do estádio obtido de $12,9 \%$ (4 em 31), elegendo possíveis candidatos para tratamento adjuvante, o que por si só justifica a apresentação.

Sem dúvida, o trabalho contribui para a divulgação do método em nosso meio e abre novas linhas de pesquisas, visando aprimorar o estádio e, com isso, propor novas opções terapêuticas.

José Hyppolito da SILVA*

\footnotetext{
* Disciplinas de Cirurgia do Aparelho Digestório e de Coloproctologia da Faculdade de Medicina da Universidade de São Paulo, São Paulo, SP.
} 
Silva JH. Sentinel lymph node detection in colorectal cancer. Arq Gastroenterol. 2006;43(3):161-2.

HEADINGS - Colorectal neoplasms. Neoplasm staging. Lymphatic metastasis. Sentinel lymph node biopsy.

\section{REFERÊNCIA BIBLIOGRÁFICA}

1. Basilio P, Fonseca LMB. Detecção de linfonodo sentinela no câncer colorretal -importância, técnica e resultados. Arq Gastroenterol. 2006;43:163-7.

\section{LEITURAS RECOMENDADAS}

Liefers GJ, Cleton-Jansen AM, van de Velde CJ, Hermans J, van Krieken, Cornelisse CJ, Tollenar RA. Micrometastases and survival in grade II colorectal câncer. N Engl J Med. 1998;339:223-8

Saha S, Espinosa M, Gauthier J, Morrison A, Rohatgi C, Dorman S, Ganatra BK, Desai D, Arora M. Diagnostic and therapeutic implications of sentinel node mapping in colorecta cancer. $51^{\text {st }}$ Society of Surgical Oncology, $1^{\text {st }}$ World Federation of Surgical Oncology Societies Cancer Synposium. San Diego, Calif, March 26-29, 1998.:p.31
Saha S, Sehgal R, Patel M, Wiese D, Bilchik A, Beutler T, Iddings D, Espinosa M, Yee C, Ghanem M. Benefits, limitations and pitfalls of sentinel lymph node (SLN) mapping (M) for colorectal carcinoma (CRCa): a multicenter trial. J Clin Oncol. 2006 ASCO Annual Meeting Proceedings Part I. 24 (188) (june 20 Supplement). General Poster Session [3621].

Silva JH. Linfocintilografia pélvica. Contribuição ao estadiamento pré-operatório do câncer retal [tese]. São Paulo: Faculdade de Medicina da Universidade de São Paulo; 1996. 